\title{
Effect of Aging Treatment on Hydrogen Embrittlement of Drawn Pearlitic Steel Wire
}

\author{
Daisuke HIRAKAMI ${ }^{1,8) *}$ Toshiyuki MANABE ${ }^{2)}$ Kohsaku USHIODA, ${ }^{3,8)}$ Kei NOGUCHI, ${ }^{4}$ Kenichi TAKAI, ${ }^{5)}$ \\ Yoshinori HATA, ${ }^{6)}$ Satoshi HATA ${ }^{7)}$ and Hideharu NAKASHIMA ${ }^{7)}$
}

1) Bar \& Wire Rod Reseach Lab., Steel Research Laboratories, Nippon Steel \& Sumitomo Metal Corporation, 20-1 Shintomi, Futtsu City, Chiba Prefecture, 293-8511 Japan. Kimitsu, Kimitsu City, Chiba, 299-1141 Japan.

2) Kimitsu R\&D Labs., Nippon Steel \& Sumitomo Metal Corporation, 1 (20-1 Shintomi, Futtsu City, Chiba, 293-8511 Japan. 4) Graduate Student, Sophia University, 7-1 Kioi-

5) Department of Engineering and Applied Science, Faculty of Science and Technology, Sophia University, 7-1 Kioicho, Chiyoda-ku, Tokyo, 102-8554 Japan.

6) Department of Molecular and Materials Sciences, Interdisciplinary Graduate School of Engineering Sciences Kyushu University, 6-1, Kasuga-koen, Kasuga, Fukuoka, 816-8580 Japan. $\quad$ 7) Department of Electrical and Materials Science, Faculty of Engineering Sciences Kyushu University, 6-1, Kasuga-koen, Kasuga, Fukuoka, 816-8580 Japan. $\quad$ 8) Graduate School of Natural Science and Technology, Kanazawa University, Kakuma-machi, Kanazawa, Ishikawa, 920-1192 Japan.

(Received on December 25, 2015; accepted on January 18, 2016; originally published in Tetsu-toHagané, Vol. 101, 2015, No. 1, pp. 59-64)

\begin{abstract}
Hydrogen embrittlement has become a crucial issue with the promotion of high-strength steel. As-drawn pearlitic steel wire is well known to have superior resistance to hydrogen embrittlement. The resistance to hydrogen embrittlement is clarified as being further improved by aging treatment at $100-{ }^{\circ} \mathrm{C}$ and $300-{ }^{\circ} \mathrm{C}$ for 10-min. of as-drawn 0.8 mass $\%$ C pearlitic steel wire with $\varphi 5.0 \mathrm{~mm}(\varepsilon=1.9)$. The higher the aging temperature is, the better the resistance to hydrogen embrittlement becomes. Simultaneously, the strength even increased slightly by aging treatment. The mechanism is investigated by exploiting thermal desorption analysis (TDA) and the newly developed TEM precession analysis. Aging at $100-^{\circ} \mathrm{C}$ led to a decrease in the hydrogen content at peak I around $100-^{\circ} \mathrm{C}$ in the TDA curve, which is inferred to be caused by $\mathrm{C}$ segregation to dislocations resulting in improvement of hydrogen embrittlement. Aging at $300-^{\circ} \mathrm{C}$ further improved the resistance to hydrogen embrittlement, which is presumably brought about by the local recovery of the heterogeneously deformed lamellar ferrite area together with the $\mathrm{C}$ segregation to dislocations. Here, the strength increased slightly by aging due to the softening factor of recovery and the hardening factor of strain aging.
\end{abstract}

KEY WORDS: hydrogen embrittlement; delayed fracture; hydrogen analysis; hydrogen trapping site; highstrength steel; pearlite steel; drawn wire.

\section{Introduction}

Recent years have seen higher strengthening of steels for lightening automobiles and reducing structure construction costs. Hydrogen embrittlement is a hindrance to the higher strengthening of steels. Therefore, research has been conducted to clarify the hydrogen embrittlement mechanism of high-strength bolt steel and to improve its hydrogen embrittlement resistance. ${ }^{1)}$ When the amount of hydrogen entering the steel from the environment exceeds the critical diffusible hydrogen content, hydrogen embrittlement occurs. ${ }^{2)}$ Here, the critical diffusible hydrogen content is the hydrogen content that depends on the strength of the steel and the stress state. The presence of more diffusible hydrogen causes the hydrogen embrittlement of the steel. Hydrogen in steel exists not only at interstitial sites but also at vacancies,

* Corresponding author: E-mail: hirakami.9fc.daisuke@jp.nssmc.com DOI: http://dx.doi.org/10.2355/isijinternational.ISIJINT-2015-735 voids, dislocations and precipitate interfaces. ${ }^{3-5)}$ Hydrogen present at interstitial sites diffuses easily at room temperature. Therefore, in tempered martensitic steel under tensile stress, for example, hydrogen present at interstitial sites diffuses and accumulates near prior austenite grain boundaries, to reduce grain boundary strength, and cause hydrogen embrittlement. ${ }^{6}$ Hydrogen at fine precipitate interfaces is trapped in strain fields and diffuses with difficulty, resulting in improved hydrogen embrittlement resistance. ${ }^{7,8)}$ On the other hand, hydrogen interacts with vacancies formed by plastic deformation and then stabilizes. ${ }^{9}$ It also becomes trapped in dislocation strain fields or dislocation cores. ${ }^{9-11)}$

The drawn pearlite steels have excellent resistance to hydrogen embrittlement. ${ }^{12)}$ However, the mechanism whereby the hydrogen embrittlement resistance of the drawn pearlite steel is improved remains unclear. The drawn pearlite steel has the lamellae structure oriented in the drawing direction. Since high-density dislocations are introduced, it is important to clarify the relationship between these micro- 
structural factors and hydrogen embrittlement resistance. More specifically, it becomes necessary to consider the effects of the $\langle 110\rangle$ fiber structure and lamellar cementite elongated in the drawing direction on toughness and the competitive phenomenon between the behavior of hydrogen being trapped by introduced dislocations and the behavior of carbon segregation to dislocations.

Thermal desorption analysis (TDA) is a well-known microscopic experimental technique used to analyze the existing state of hydrogen in steel. ${ }^{13)}$ The TDA of the drawn pearlite structure shows the peak 1 hydrogen near $100^{\circ} \mathrm{C}$ and the peak 2 hydrogen near $300^{\circ} \mathrm{C}$. This means that there are multiple hydrogen trap sites. ${ }^{14)}$ Doshida and Takai ${ }^{15)}$ explain that stretching steel in the presence of peak 1 hydrogen generates lattice defects and consequently increases the hydrogen embrittlement susceptibility. Chida et al. ${ }^{16)}$ report that the $250^{\circ} \mathrm{C}$ and $450^{\circ} \mathrm{C}$ aging treatment of the drawn pearlite steel decreases the peak 1 hydrogen content and increases the critical diffusible hydrogen content. According to them the aging treatment caused the segregation of carbon to dislocations introduced during wire drawing and decreased the trapped hydrogen content by dislocations. It is also inferred that the $450^{\circ} \mathrm{C}$ aging treatment causes recovery, and hence decreases the strength and increases the hydrogen embrittlement resistance. However, detailed microstructural analysis has not been conducted on the manner of recovery and carbide precipitation to dislocations, among other things. The decrease in the trapped hydrogen content with aging in a dry-wet cyclic corrosion test ${ }^{17)}$ can be explained by the segregation of carbon to dislocations, but the reason why the critical diffusible hydrogen content increases is not necessarily evident.

Many studies have been conducted on the microstructural change of severely worked pearlite steels. ${ }^{18-20)}$ Lamellar cementite is oriented in the drawing direction as the wire drawing reduction increases. The cementite oriented nearly perpendicular to the drawing direction before the drawing operation is curved, and the shear band develops as the strain increases. ${ }^{21)}$ It is reported that as the amount of strain approaches 4, lamellar ferrite is nanocrystallized and that cementite becomes amorphous. $^{22)}$ The changes in microstructure, mechanical properties and hydrogen embrittlement resistance with aging at a relatively low temperature of 100 to $300^{\circ} \mathrm{C}$ for a relatively short time of $10 \mathrm{~min}$ after wire drawing with a strain of close to 2 as in the present study have not yet been elucidated.

The present study thus endeavored to deepen the understanding of the effect of aging on the hydrogen embrittlement susceptibility of the drawn pearlite steel from the viewpoint of microstructural change. Namely, it was designed to observe dislocation structures and carbide in as-drawn and drawn and aged pearlite steel specimens by transmission electron microscopy (TEM) and to perform grain orientation analysis (TEM orientation mapping) ${ }^{23)}$ of minute regions by the nanobeam precession electron diffraction method. It ultimately aimed at clarifying the correlation between the change in microstructure with aging and hydrogen embrittlement susceptibility of the drawn pearlite steel.

\section{Experimental}

\subsection{Material}

The high-carbon steel SWRS82B (0.8 mass\%C steel) was used as experimental material. First, a 122 by $122 \mathrm{~mm}$ billet of the SWRS82B steel was heated to $1100^{\circ} \mathrm{C}$ and hot rolled into a $\phi 13.0 \mathrm{~mm}$ rod. The microstructure of the as-rolled material was pearlite. Its chemical composition is given in Table 1.

The pearlite steel rod was heated at $880^{\circ} \mathrm{C}$ for $10 \mathrm{~min}$ and held at $530^{\circ} \mathrm{C}$ for $120 \mathrm{~s}$ to induce pearlite transformation. The heat-treated rod was pickled, zinc phosphated and dry drawn to $\phi 5.0 \mathrm{~mm}$ at room temperature. Some of the drawn wires were used as as-drawn specimens. The rest were aged at $100^{\circ} \mathrm{C}$ for $10 \mathrm{~min}(\mathrm{BL} 100)$ or at $300^{\circ} \mathrm{C}$ for 10 min (BL300). Table 2 shows the tensile strength of the specimens. As the table shows, the $100^{\circ} \mathrm{C}$ and $300^{\circ} \mathrm{C}$ aging treatments increased the tensile strength of the BL100 and BL300 specimens by about $100 \mathrm{MPa}$ as compared with that of the as-drawn specimens.

\subsection{Methods for Evaluating Hydrogen Embrittlement of Drawn Pearlite Steel}

The $\phi 5 \mathrm{~mm}$ SWRS82B specimens prepared as described in 2.1 were tested by the slow strain rate test (SSRT) to investigate the effect of the aging treatment on the hydrogen embrittlement of the drawn pearlite steel. The SSRT specimens were each prepared by cutting a round rod to a length of $300 \mathrm{~mm}$, circumferentially notching the rod at $140 \mathrm{~mm}$ from the end and to a depth of $0.4 \mathrm{~mm}$, an angle of $60^{\circ}$ and a radius of curvature of $0.12 \mathrm{~mm}$. The specimens were polished with emery paper to remove the oxide film. Some specimens were not hydrogen charged. The rest were hydrogen pre-charged to saturation at a current density of 2 to $5 \mathrm{~A} / \mathrm{m}^{2}$. The specimens were slow strain rate tested at a crosshead speed of 0.0005 to $50 \mathrm{~mm} / \mathrm{min}$. The slow strain rate test was conducted under continuous hydrogen charging to keep the hydrogen concentration of the pre-charged specimens constant. The fracture stress ratio of the hydrogen pre-charged specimens to the hydrogen uncharged specimens was obtained, and the effect of the aging treatment was evaluated using the fracture stress ratio as the index of delayed fracture.

The shape of the specimens used in the constant load test was the same as that of the circumferentially notched round rod specimens used in the SSRT. The specimens were also polished with emery paper to remove the oxide

Table 1. Chemical composition of the steel used (mass\%).

\begin{tabular}{cccccccccc}
\hline & $\mathrm{C}$ & $\mathrm{Si}$ & $\mathrm{Mn}$ & $\mathrm{P}$ & $\mathrm{S}$ & $\mathrm{Cr}$ & $\mathrm{Mo}$ & $\mathrm{N}$ & $\mathrm{O}$ \\
\hline SWRS82B & 0.82 & 0.19 & 0.75 & 0.017 & 0.015 & - & - & 0.0035 & 0.0015 \\
\hline
\end{tabular}

Table 2. Tensile strength of as-drawn and as-aged wires for $10 \mathrm{~min}$ at $100^{\circ} \mathrm{C}(\mathrm{BL} 100)$ and $300^{\circ} \mathrm{C}(\mathrm{BL} 300)$.

\begin{tabular}{cc}
\hline Sample & Tensile strength $(\mathrm{MPa})$ \\
\hline as-drawn & 1943 \\
BL100 & 2029 \\
BL300 & 2038 \\
\hline
\end{tabular}


film. The specimens were then pre-charged with hydrogen and constantly loaded, and their time to fracture was investigated. To keep constant the hydrogen concentration of the hydrogen pre-charged specimens, the constant loading test was conducted under continuous hydrogen charging as the SSRT.

Hydrogen was occluded in the specimens by the electrolytic hydrogen charging method with a solution of $0.1 \mathrm{~N}$ $\mathrm{NaOH}+5 \mathrm{~g} / \mathrm{L} \mathrm{NH}_{4} \mathrm{SCN}$, a current density of $2 \mathrm{~A} / \mathrm{m}^{2}$, and a temperature of $30^{\circ} \mathrm{C}$.

\subsection{Method for Analyzing Hydrogen in Steel}

The hydrogen analysis was conducted by TDA using gas chromatography. The specimens were ultrasonically washed in acetone before the measurement. Each specimen was dried and placed in the quartz tube of the heating chamber. After the atmosphere in the quartz tube was replaced by the argon carrier gas, the measurement was started. The time from the acetone washing to the start of the measurement was within $10 \mathrm{~min}$. The heating rate was $100^{\circ} \mathrm{C} / \mathrm{hr}$ and the measurement was conducted at temperatures up to $600^{\circ} \mathrm{C}$.

\subsection{Microstructural Observation and Grain Orienta- tion Mapping Method by TEM}

The drawn specimens were observed by TEM to investigate microstructural change with aging. The as-drawn specimens and as-aged specimens were cut to $\phi 5.0 \mathrm{~mm} \times 10 \mathrm{~mm}$ and punched to $\phi 3.0 \mathrm{~mm}$ disks with their center located at a depth of $1.5 \mathrm{~mm}$ from the outer circumference. Thin film specimens were prepared by mechanical polishing and twinjet electrolytic polishing. They were then observed by TEM. This study is also characterized in that the grain orientation distribution of the $\alpha$-Fe phase is mapped by the nanobeam precession electron diffraction method whereby the electron beam is precessed on the specimen (beam irradiation diameter of about $10 \mathrm{~nm}$ and incident angle of $0.6^{\circ}$ ). Namely, an electron beam with a spot size of $10 \mathrm{~nm}$ was automatically scanned at a step size of $10 \mathrm{~nm}$ to obtain electron diffraction spots representing grain orientations. The TEM observation surface includes the longitudinal drawing direction.

\subsection{Measurement of Dislocation Density by X-ray Dif- fraction}

The dislocation density was measured at the quarter depth

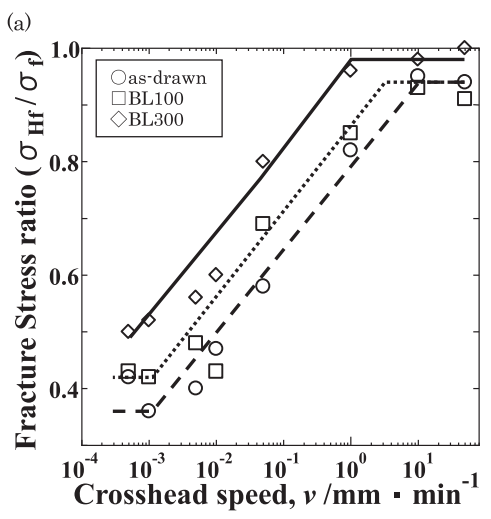

of specimens cut longitudinally. The dislocation density was calculated by the Williamson-Hall method. ${ }^{24)}$

\section{Experimental Results}

\subsection{Change in Hydrogen Embrittlement of Drawn Pearlite Steel with Aging}

Figure 1 shows the hydrogen embrittlement characteristics of as-drawn specimens and drawn and aged specimens of the steel SWRS82B (0.8 mass\% C steel). As shown in Fig. 1(a), in the crosshead speed range of $10^{-3}$ to $10^{0} \mathrm{~mm} / \mathrm{min}$ in the SSRT, the fracture stress ratio decreases in each specimen with the decrease in the crosshead speed of the tensile test, in other words, with the decrease in the strain rate. Also, the fracture stress ratio of the drawn and aged specimens is higher than that of the as-drawn specimens at each crosshead speed.

In the constant load tensile test results shown in Fig. 1(b), the time to fracture increased in each specimen as the ratio of applied stress to fracture stress of the hydrogenuncharged specimens (or the applied stress ratio) was decreased. As compared with the as-drawn specimens, the drawn and aged specimens increased in the fracture stress ratio at the same time to fracture.

\subsection{Change in Hydrogen Trap State with Aging of Drawn Pearlite Steel}

Figure 2 shows the relationship between the hydrogen

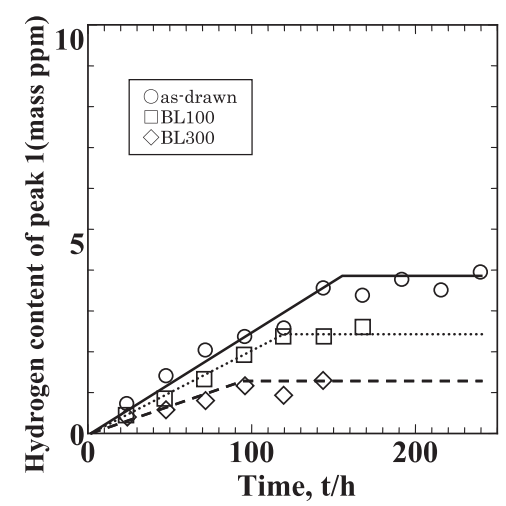

Fig. 2. Effect of aging treatment on the hydrogen content of peak 1 in the TDA test as a function of the hydrogen charging time.

(b)

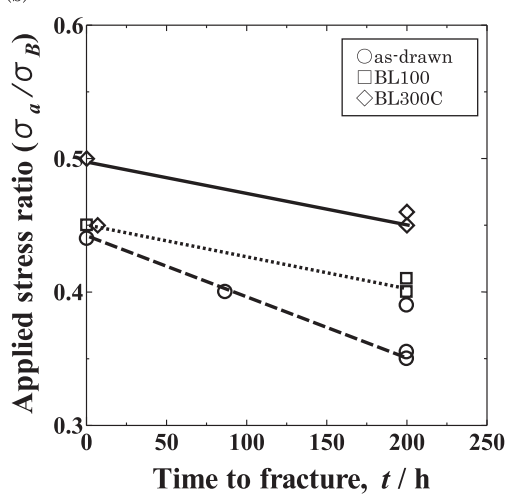

Fig. 1. (a) Fracture stress ratio $\left(\sigma_{\mathrm{Hf}} / \sigma_{\mathrm{f}}\right)$ as a function of cross -head speed in the SSRT test, and (b) applied stress ratio $\left(\sigma_{\mathrm{a}} / \sigma_{\mathrm{f}}\right)$ as a function of time to fracture in the constant-load tensile test of specimens as-drawn and as-aged at $100^{\circ} \mathrm{C}$ and $300^{\circ} \mathrm{C} . \sigma_{\mathrm{Hf}}$ and $\sigma_{\mathrm{f}}$ are fracture stresses with and without hydrogen charging. $\sigma_{\mathrm{a}}$ is applied stress in the constant-load tensile test. 

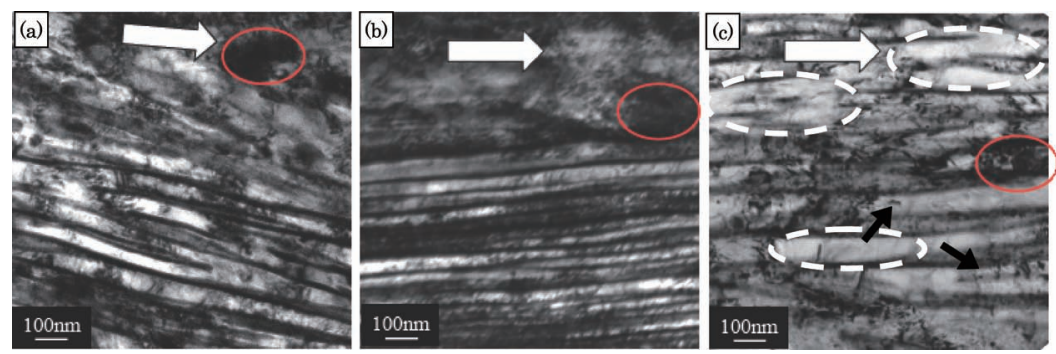

Fig. 3. TEM images showing the dislocation structure of specimens of (a) as-drawn, (b) as-aged at $100^{\circ} \mathrm{C}$, and (c) asaged at $300^{\circ} \mathrm{C}$. White arrows indicate the drawing direction. Black arrows stand for the carbides. Dotted circles show the area where dislocations are rearranged.
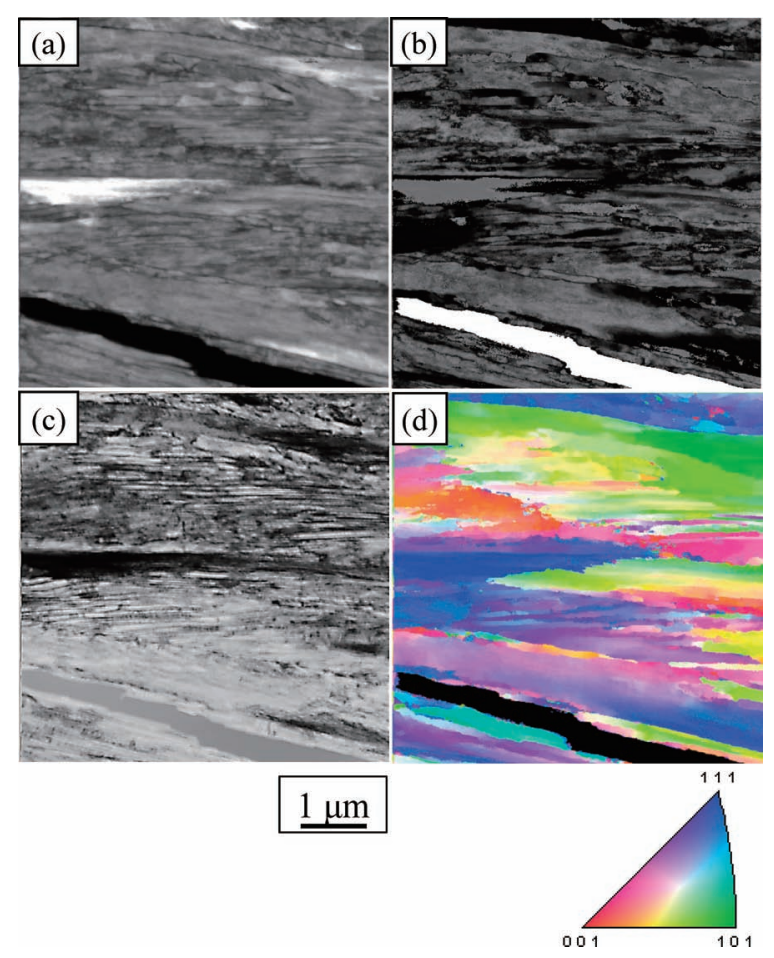

Fig. 4. TEM precession analyses of as-drawn wire. (a) Index map, (b) reliability map, (c) virtual BF image, and (d) grain orientation map.

charging time and TDA peak 1 hydrogen content near $100^{\circ} \mathrm{C}$ of SWRS82B $(0.8$ mass $\% \mathrm{C}$ steel) specimens electrolytically charged with hydrogen at $2 \mathrm{~A} / \mathrm{m}^{2}$. The saturated hydrogen content is 4.0 mass ppm for the as-drawn specimens, 2.5 mass ppm for the drawn and $100^{\circ} \mathrm{C}$ aged specimens and 1.0 mass ppm for the drawn and $300^{\circ} \mathrm{C}$ aged specimens. Therefore, the saturated hydrogen content decreases with the increase in aging temperature.

\subsection{Microstructural Change of Drawn Pearlite Steel with Aging}

Figure 3 shows the longitudinal section TEM bright field images of as-drawn specimens, $100^{\circ} \mathrm{C}$ aged specimens and $300^{\circ} \mathrm{C}$ aged specimens of the drawn pearlite steel. The drawing direction is indicated by the white arrows. Dislocations were observed in lamellar ferrite straddling lamellar cementite in each specimen. The width of lamellar ferrite is 50 to $100 \mathrm{~nm}$ in each specimen. No clear changes were observed in the ferrite phase width and cementite structure with the aging treatment. The $300^{\circ} \mathrm{C}$ aged specimens, however, produced images suggesting progress in the rearrangement of dislocations in lamellar ferrite as indicated by the
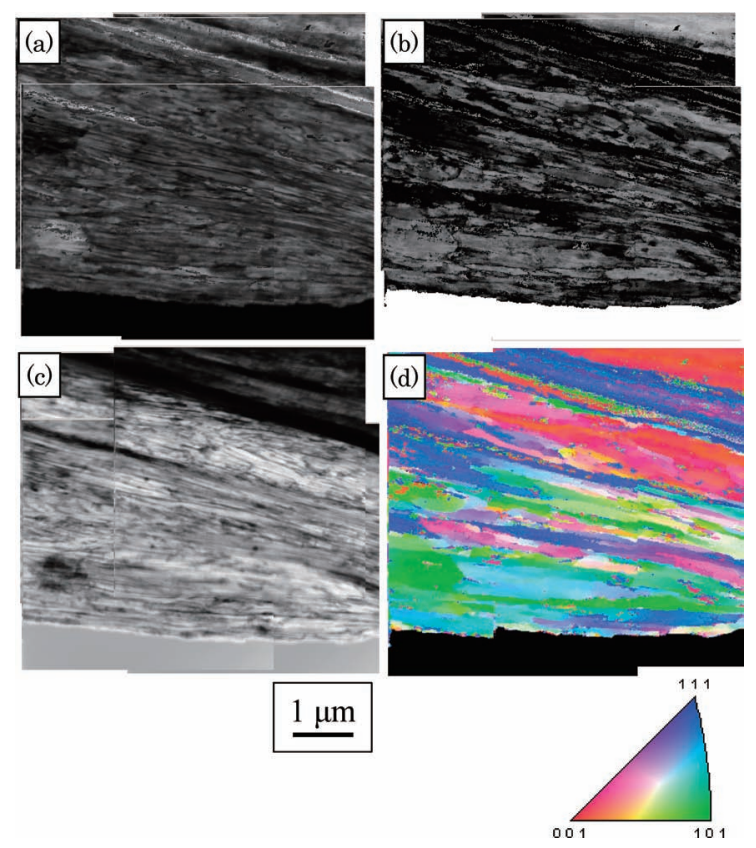

Fig. 5. TEM precession analyses of $100^{\circ} \mathrm{C}$ aging wire. (a) Index map, (b) reliability map, (c) virtual BF image, and (d) grain orientation map.

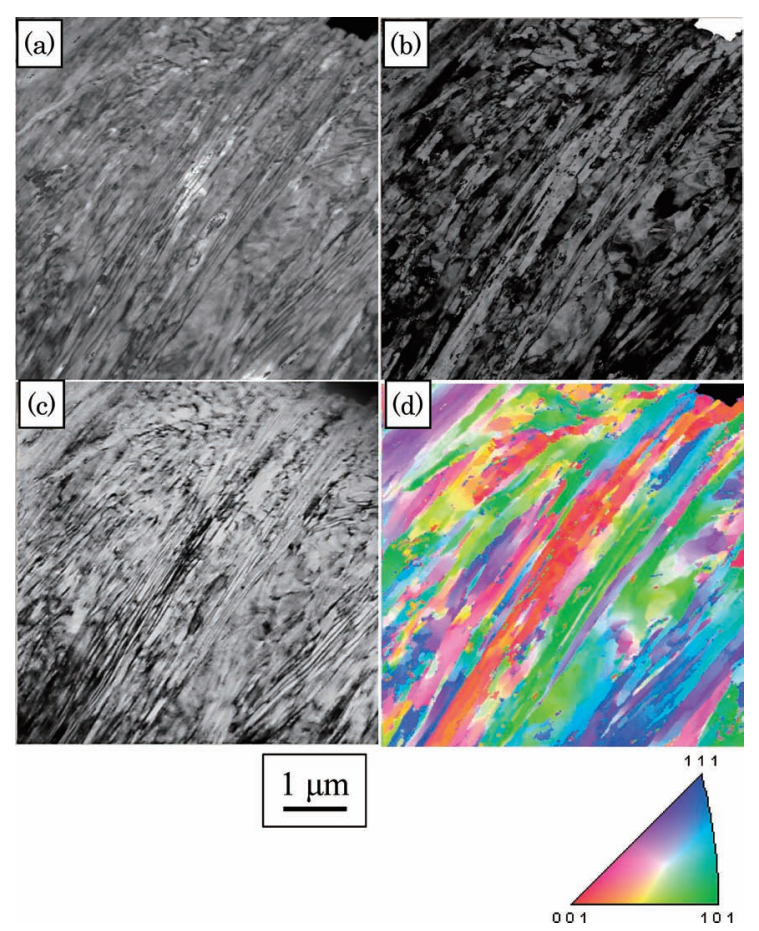

Fig. 6. TEM precession analyses of $300^{\circ} \mathrm{C}$ aging wire. (a) Index map, (b) reliability map, (c) virtual BF image, and (d) grain orientation map. 
broken line circles in Fig. 3(c). Contrast was also observed suggesting the precipitation of carbides as indicated by the black arrows in Fig. 3(c). Strain contrast arising from the localized presence of high-density dislocations was also seen as indicated by the circles in Figs. 3(a) to 3(c), but no clear difference was observed regarding whether the specimens were aged.

Figures 4, 5 and 6 show the ferrite phase orientation analyses by precession electron diffraction of the as-drawn specimens, $100^{\circ} \mathrm{C}$ aged specimens and $300^{\circ} \mathrm{C}$ aged specimens of the drawn pearlite steel, respectively. Common to Figs. 4 to 6, Fig. (a) is an index map. It is a contrast that shows the experimentally obtained diffraction pattern and the position and intensity differences calculated from the diffraction pattern. Figure (b) is a reliability map. The diffraction spots are indexed in multiple patterns. The reliability map shows the reliability difference between apparently the most reliable indexing and the next most reliable indexing. The bright regions are those of high analytical reliability. Figure (c) is a virtual bright field image obtained by the nanobeam precession electron diffraction method. Figure (d) is a grain orientation map where the diffraction spots are indexed by ferrite and analyzed. In the grain orientation map (d) of each specimen, grains of the same color are elongated in the drawing direction. This means that the grains are elongated by the drawing operation in the drawing direction. Regions of the same color in the grain orientation map are inferred to be initial block regions approximately 1 to $2 \mu \mathrm{m}$ wide in the drawing direction. Grain orientation gradations in the blocks are inferred to reflect packets. In this way, the inhomogeneity of the drawn microstructure is related to the grain orientations of the blocks before the drawing operation. The packets are considered to bring about the gradations of the grain orientations. In the grain orientation map of the $300^{\circ} \mathrm{C}$ aged specimen shown in Fig. 6 , some regions of fine microstructure with high-angle grain boundaries were observed, as compared with the as-drawn specimen and $100^{\circ} \mathrm{C}$ aged specimen. In the reliability map (b) and the grain boundary map (d), the fine-grained regions are in good correlation. These analytical results suggest that in some regions of heavily worked ferrite grains, the $300^{\circ} \mathrm{C}$ aging treatment caused local recovery, or decreased the dislocation density through dislocation annihilation and rearrangement, and promoted subgrain formation or recrystallization.

\section{Discussion}

Takai and Watanuki ${ }^{14)}$ indicate that the TDA of the drawn pearlite steel points to the presence of peak 1 hydrogen near $100^{\circ} \mathrm{C}$ and of peak 2 hydrogen near $300^{\circ} \mathrm{C}$. Doshida and Takai ${ }^{15)}$ explain that plastic deformation of the drawn pearlite steel increases the hydrogen embrittlement susceptibility and that this condition is correlated to the increase in the peak 1 hydrogen content. Chida et al. ${ }^{17)}$ indicate that aging the drawn pearlite steel decreases the peak 1 hydrogen content. For example, aging at $250^{\circ} \mathrm{C}$ for 30 min greatly reduces the peak 1 hydrogen content. Carbon is considered to be trapped in the dislocations resulting in decreasing the number of hydrogen trap sites. Figure 2 in the present study shows results similar to those of Chida et al. The peak 1 hydrogen content decreased after aging at $100^{\circ} \mathrm{C}$ for $10 \mathrm{~min}$. Chida et al. ${ }^{16)}$ report that aging at $250^{\circ} \mathrm{C}$ for $30 \mathrm{~min}$ increases the diffusible hydrogen content only slightly and the number of hydrogen trap sites is decreased by the segregation of carbon to dislocations. The $450^{\circ} \mathrm{C}-30 \mathrm{~min}$ aging treatment substantially increased the critical diffusible hydrogen content but decreased the strength as well. This was explained as the effect of recovery in improving toughness. Aging for a relatively short period of $10 \mathrm{~min}$ as in the present study does not change the strength of the drawn pearlite steel as shown in Table 2, but considerably decreases its hydrogen embrittlement susceptibility as shown in Fig. 1. The effect of microstructural change is considered to have added to the segregation of carbon to the dislocations. As shown in Fig. 3, the dislocations introduced by working into lamellar ferrite are not uniform. There are regions where the dislocation density is locally high. The presence of these regions is predicted to increase the hydrogen embrittlement susceptibility as investigated by Suzuki and Takai, ${ }^{13)}$ and Doshida and Takai. ${ }^{15)}$ Chida et al., ${ }^{17)}$ however, reported that aging is expected to decrease the hydrogen embrittlement susceptibility. The TEM grain orientation maps of minute regions of the as-drawn specimen and $300^{\circ} \mathrm{C}$ aged specimen are comparatively shown in Figs. 4 and 6, respectively. Both specimens have the grains elongated in the drawing direction, but the $300^{\circ} \mathrm{C}$ aged specimen has the dislocations rearranged more advantageously. Furthermore, the TEM grain orientation maps clarified for the first time the formation of a fine microstructure with high-angle grain boundaries where recovery partially progressed and subgrain formation or recrystallization apparently proceeded. This suggests the possibility that the high-strain regions mentioned earlier locally recovered or recrystallized as a result of aging at $300^{\circ} \mathrm{C}$ for $10 \mathrm{~min}$. This microstructural recovery process produces softening, but it is necessary to note that slight hardening actually occurred.

Figure 7 shows the results of dislocation density measurement conducted by X-ray diffraction to indirectly evaluate the aging-induced recovery or recrystallization behavior. The dislocation density was changed slightly by aging at $100^{\circ} \mathrm{C}$ for $10 \mathrm{~min}$, suggesting the decoration of the dislocations with carbon. Aging at $300^{\circ} \mathrm{C}$ for $10 \mathrm{~min}$, on the other hand, slightly decreased the dislocation density. The possibility of local recovery or recrystallization is inferred from these results in combination with the TEM grain orientation mapping results.

The mechanism whereby the hydrogen embrittlement resistance of the drawn pearlite steel was improved by its

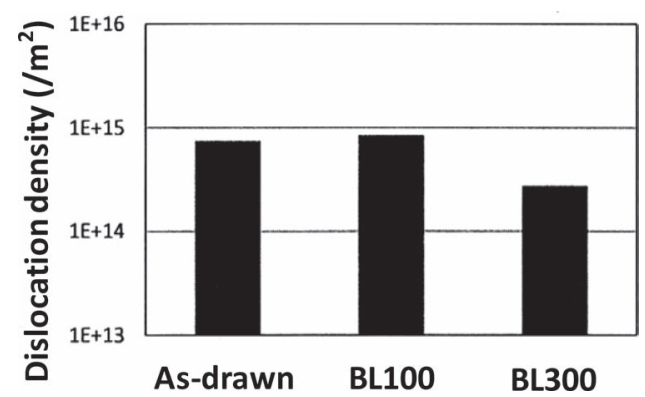

Fig. 7. Dislocation density of specimens of (a) as-drawn, (b) asaged at $100^{\circ} \mathrm{C}$, and (c) as-aged at $300^{\circ} \mathrm{C}$. 

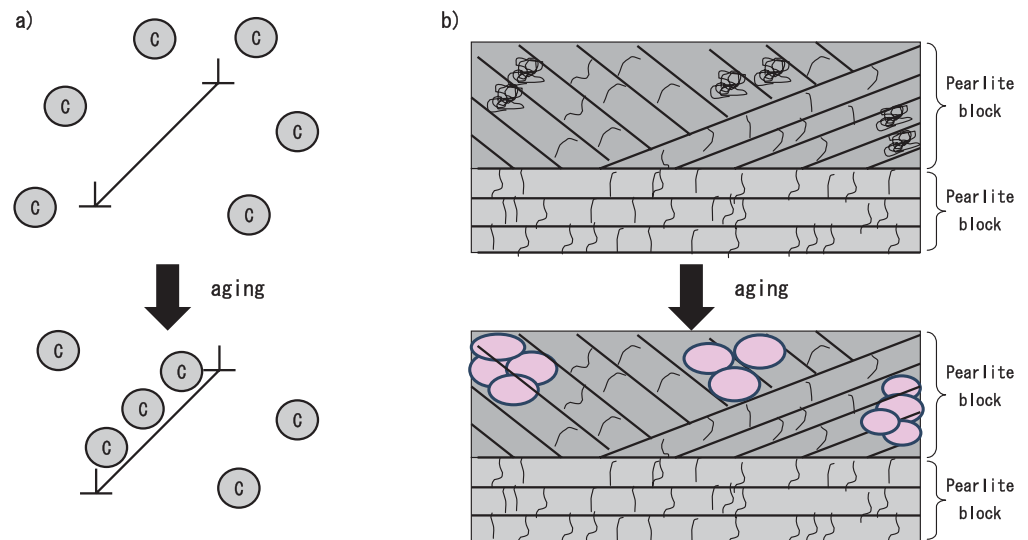

Fig. 8. Schematic illustrations showing the mechanism of improvement of hydrogen embrittlement by aging at a) $100^{\circ} \mathrm{C}$ and b) $300^{\circ} \mathrm{C}$ of as-drawn wire.

aging treatment is schematically illustrated in Fig. 8. When the drawn pearlite steel is aged at $100^{\circ} \mathrm{C}$ for $10 \mathrm{~min}$, carbon segregates to the dislocations as described by Chida et al. The hydrogen embrittlement susceptibility is consequently reduced. At the same time, strain age hardening was considered to have increased the strength (Fig. 8(a)). When the drawn pearlite steel is aged at $300^{\circ} \mathrm{C}$ for $10 \mathrm{~min}$, carbon further segregates to the dislocations and carbides precipitate to the dislocations. The hydrogen embrittlement susceptibility should be essentially high in the high-strain regions where dislocations are tangled in a complex manner as shown in the upper part of Fig. 8(b). Aging at $300^{\circ} \mathrm{C}$ for $10 \mathrm{~min}$, however, induces the local recovery or subgrain formation and recrystallization of the regions enclosed with the circles in the lower part of Fig. 8(b). The hydrogen embrittlement susceptibility is thus inferred to have decreased to improve the hydrogen embrittlement resistance. The above-mentioned recovery or recrystallization causes the strength to decline, but is also expected to cause strain age hardening. Therefore, there was no strength decline.

\section{Conclusions}

The hydrogen existing state and hydrogen embrittlement of as-drawn, $100^{\circ} \mathrm{C}-10 \mathrm{~min}$ aged and $300^{\circ} \mathrm{C}-10 \mathrm{~min}$ aged specimens of the drawn 0.8 mass $\% \mathrm{C}$ pearlite steel was investigated by thermal desorption analysis (TDA), hydrogen embrittlement susceptibility evaluation, and dislocation substructure observation as well as grain orientation mapping by nanobeam precession electron diffraction by TEM. The following findings were obtained:

(1) The aging treatment of the drawn 0.8 mass $\% \mathrm{C}$ pearlite steel decreased its hydrogen embrittlement susceptibility. This tendency strengthened with the increase in the aging temperature from $100^{\circ} \mathrm{C}$ to $300^{\circ} \mathrm{C}$.

(2) The aging treatment of the drawn 0.8 mass $\% \mathrm{C}$ pearlite steel decreased the TDA peak 1 hydrogen content of specimens electrolytically charged with hydrogen. This tendency strengthened with the increase in aging temperature.

(3) High-dislocation density regions existed in the microstructure of the drawn 0.8 mass $\% \mathrm{C}$ pearlite steel. The $300^{\circ} \mathrm{C}$ aging treatment accelerated the localized recovery or recrystallization of these regions.

(4) The above experimental results indicate that the segregation of carbon to the dislocations decreased the hydrogen embrittlement susceptibility and increased the strength of the drawn 0.8 mass $\% \mathrm{C}$ pearlite steel when aged at $100^{\circ} \mathrm{C}$. The hydrogen embrittlement resistance of the drawn 0.8 mass $\% \mathrm{C}$ pearlite steel aged at $300^{\circ} \mathrm{C}$, on the other hand, was improved by the reduction of embrittled regions by the localized recovery or recrystallization of high-strain regions as well as by the further segregation of carbon to the dislocations. It was also inferred that softening by recovery and hardening by strain aging combined to increase the strength on the whole.

\section{Acknowledgments}

Part of this study was conducted under a grant-in-aid for scientific research.

\section{REFERENCES}

1) Y. Namimura: Tokushukou, 52 (2008), 32

2) S. Matsuyama: Okurehakai, Nikkan Kogyou Shinbunsya, Tokyo, (1989), 70 .

3) K. Takai, S. Hirota, H. Suzuki, Y. Seko and H. Motohashi: J. Jpn. Inst. Met., 77 (2013), 615.

4) H. G. Lee and J.-Y. Lee: Acta Metall., 32 (1984), 131.

5) H. Yaguchi, T. Kochi, M. Nomura and T. Watanabe: J. Jpn. Inst. Met., 71 (2007), 781

6) S. K. Banerji, C. J. McMahon, Jr. and H. C. Feng: Metall. Trans. A, 9 (1978), 237

7) M. Nagao and H. Yaguchi: Process Metallurgy and Properties of Modern Structural Steels, Interdisciplinary Technical Committee Report, ISIJ, Tokyo, (2000), 38.

8) J. Takahashi, K. Kawakami, Y. Kobayashi and T. Tarui: Scr. Mater., 63 (2010), 261.

9) M. Nagumo: Suisozeika-no-Kiso, Uchida Rokakuho, Tokyo, (2008), 299.

10) H. Hagi: Materia Jpn., 33 (1994), 1407.

11) E. Enomoto, D. Hirakami and T. Tarui: Metall. Mater. Trans. A, 43A (2012), 572.

12) K. Takai, J. Seki and Y. Honma: Tetsu-to-Hagané, 81 (1995), 1025.

13) H. Suzuki and K. Takai: ISIJ Int., 52 (2012), 174.

14) K. Takai and R. Watanuki: ISIJ Int., 43 (2003), 520.

15) T. Doshida and K. Takai: Acta Mater., 79 (2014), 93.

16) T. Chida, M. Kosaka, M. Kubota and T. Tarui: CAMP-ISIJ, 19 (2006), 1158.

17) T. Chida, M. Kosaka, M. kubota and T. Tarui: CAMP-ISIJ, 18 (2005), 559.

18) Y. Daitou and T. Hamada: Tetsu-to-Hagané, 86 (2000), 105.

19) K. Makii and N. Ibaraki: Workshop of STX-21, NIMS, Ibaraki, (1998), 100.

20) K. Hono, M. Ohmura, M. Murayama, S. Nishida, A. Yoshie and T. Takahashi: Scr. Mater., 44 (2001), 977.

21) G. Langford and M. Cohen: Trans. Am. Soc. Met., 62 (1969), 628.

22) Y. Tomoda: Netsusyori, 43 (2003), 73.

23) P. Moeck1, S. Rouvimov1, I. Häusler, W. Neumann and S. Nicolopoulos: Ultramicroscopy, 128 (2013), 68.

24) S. Takebayashi, T. Kunieda, N. Yoshinaga, K. Ushioda and S. Ogata: ISIJ Int., 50 (2010), 875. 